\title{
Meyve ve sebze üretiminde ortaya çıkan kayıplar üzerinde etkili olan faktörler: İzmir ili örneği*
}

\section{Factors affecting losses in fruit and vegetable production: The case of İzmir province}

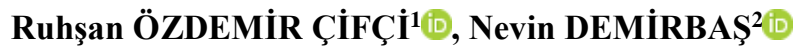

${ }^{1}$ Bornova Tarım ve Orman İlçe Müdürlüğü, İzmir

${ }^{2}$ Ege Üniversitesi, Ziraat Fakültesi, Tarım Ekonomisi Bölümü, 35100, Bornova, İzmir

Sorumlu yazar (Corresponding author): N. Demirbaş, e-posta (e-mail): nevin.demirbas@ege.edu.tr

Yazar(lar) e-posta (Author e-mail): bornova@ tarimorman.gov.tr

\section{MAKALE BILLGISİ}

Alınış tarihi 13 Aralık 2019

Düzeltilme tarihi 03 Mart 2020

Kabul tarihi 04 Mart 2020

\section{Anahtar Kelimeler:}

Gida kayıpları

Meyve

Sebze

İyi Tarım Uygulamaları (ITTU)

İzmir

\begin{abstract}
ÖZ
Bu çalışmanın amacı, meyve ve sebze üretiminde ortaya çıkan kayıplar üzerinde etkili olan faktörlerin belirlenmesidir. Bu amaçla, İzmir ilinde üretim değeri açısından göreli öneme sahip meyvelerden üzüm, kiraz ve incir ile sebzelerden domates, hıyar ve biber araștırmanın ürün kapsamına seçilmiştir. Bu ürünlerin üreticileri ile yüz yüze 146 anket yapılmıştır. Üretim aşaması; hasat öncesi, hasat aşaması ve hasat sonrası olmak üzere ürünlerin satıșına kadar olan çiftlik süreçlerini kapsamaktadır. Araştırmada, her aşamaya ilişkin kayıplar üzerinde etkili olan faktörler ayrı ayrı incelenmiş ve birlikte değerlendirilmiştir. Araştırma sonuçlarına göre, meyve ve sebzelerde ortaya çıkan kayıplar üzerinde etkili olan faktörler mevcut literatürle uyumludur. Mevsimsel faktörler, teknik bilgi eksikliği, soğuk muhafaza olanaklarının sağlanamaması ve ekonomik faktörler belli başlı kayıp nedenleridir. Araştırmada kayıpların azaltılması için alınabilecek önlemler hem genel olarak ve hem de yeri geldikçe ürün özelinde değerlendirilmiştir.
\end{abstract}

\section{ARTICLE INFO}

Received 13 December 2019

Received in revised form 03 March 2020

Accepted 04 March 2020

\section{Keywords:}

Food losses

Fruit

Vegetable

Good Agriculture Practices (GAP)

İzmir

\begin{abstract}
The aim of this study is to determine the factors affecting the losses in fruit and vegetable production. For this purpose, grapes, cherries and figs and tomatoes, cucumbers and peppers, which are of relative importance in terms of production value, were selected to the product scope of the research. 146 face-to-face surveys were conducted with farmers of these products. The production phase includes the farm processes from pre-harvest, harvest and post-harvest to the sale of products. In the study, the factors that affect the losses at each stage were examined separately and evaluated together. According to the results of the research, the factors affecting the losses in fruits and vegetables are consistent with the current literature. Seasonal factors, lack of technical knowledge, lack of cold storage facilities and economic factors are the main causes of loss. Measures that can be taken to reduce losses in the research were evaluated both in general and, where appropriate, in the specific product.
\end{abstract}

*Bu araştırma makalesi, “Meyve ve sebze üretiminde ortaya çıkan kayıpların değerlendirilmesi: İzmir ili örneği” başlıklı Yüksek Lisans tezinden üretilmiştir.

\section{Giriş}

Dünya üzerinde her yıl insan tüketimi için üretilen gıdaların yaklaşık üçte birine karşılık gelen gıda, israf edilmekte veya kayba uğramaktadır. Meyve ve sebze ürün grubu özellikleri gereği kayıp ve israfın yüksek oranlarda yaşandığı tarım ürünleridir. $\mathrm{Bu}$ ürünlerde yıllık üretimin yaklaşık yarısının tüketiciye ulaşmadığı belirtilmektedir (Gustavsson ve ark. 2011a; Demirbaş 2018a). Avrupa ülkelerinde arz zinciri boyunca ortaya çıkan meyve ve sebze kayıpları; birincil üretimde $\% 20$, hasat sonrası $\% 5$, işleme ve paketleme aşamasında $\% 2$, dağıtım ve satış aşamasında $\% 10$ ve tüketici aşamasında ise \%19 seviyelerindedir (Gustavsson ve ark. 2011b; Capone ve ark. 2016). ABD'deki gıda kayıplarının \%32.9'u meyve ve sebzelerden oluşmaktadır (Buzby ve ark. 2014). Yakın Doğu ve Kuzey Afrika bölgesinde ise çok düşük soğuk zincir kapasitesi nedeniyle, meyve ve sebzelerin miktar olarak \%45'i kayıp olmaktadır (FAO 2014; FAO 2017; Bilali 2018; Berjan ve ark. 2018). Meyve ve sebzede \%55 ile kayıpların en çok yaşandığı ülkeler Kuzey Afrika, Batı ve Orta Asya Ülkeleri iken, \%35 ile en az yaşandığı ülkeler ise sanayileşmiş Asya ülkeleridir (Gustavsson ve ark. 2011b). Hindistan'da genellikle soğuk zincirin eksikliği, uygun olmayan hasat teknikleri ve uzun arz zincirleri nedeniyle meyve ve 
sebzelerinin \%35-40'ının kayba uğradığı belirtilmektedir (Escaler ve Teng 2011).

2017 yılı FAO verilerine göre, Türkiye 30.8 milyon ton yaş sebze üretimi ile dünya üretiminde dördüncü sırada olup; dünya yaş sebze üretiminden $\% 2.8$ oranında pay almaktadır. Dünya meyve üretiminde yaklaşı olarak 23.1 milyon ton yaş meyve üretimi ile beşinci sıradadır. Dünya üretiminden aldığı pay ise \%2.7'dir (FAO 2019). Türkiye'de gıda arz zincirinin tarımsal üretim aşamasındaki toplam kayıp miktarı yaklaşık olarak 13.7 milyon ton olarak belirtilmiştir. $\mathrm{Bu}$ miktar toplam üretim miktarının yaklaşık \%12'sine karşılık gelmektedir. Meyve sebze üretiminin de yaklaşı 9.48 milyon tonunun yine tarımsal üretim aşamasında kayba uğradığı belirtilmektedir (Salihoğlu ve ark. 2018).

$\mathrm{Bu}$ çalışmanın amacı, Türkiye'de gıda kayıplarının en büyük kısmını oluşturan meyve ve sebze ürün grubu için üretim aşamasında (tarım işletmelerinde) ortaya çıkan kayıpların ve kayıpları etkileyen faktörlerin belirlenmesidir.

\section{Materyal ve Yöntem}

İzmir ilinde meyve ve sebze ürün grubunu temsil edecek ürünlerin seçimi için 2015/2017 y1lları ortalama üretim değerlerinden hareket edilmiştir. Meyve üretiminde İzmir ili toplam üretim değerinin \%40'ını oluşturan üzüm, kiraz ve incir; sebze üretimini temsilen ise il toplam üretim değerinin ortalama \%52'sini oluşturan domates, hıyar ve biber seçilmiştir (TOB 2019a). Seçilen ürünlerin her birinde en az 20 anket ile toplam anket sayısının minimum 120 olması hedeflenmiştir. Anketler için, İzmir ili üretim miktarının, seçilen ürünlerde toplamda $\% 65$ ve üzerini temsil eden ilçeler belirlenmiştir. Buna göre 14 ayrı ilçede her ürün için ortalama 24 anketten toplam 146 üretici anketi yapılmıştır (Çizelge 1).

Anket yapılan mahallelerin belirlenmesinde seçilen üründe ÇKS'de kayıtlı ekili alan verileri dikkate alınmıştır (İTOİM 2018). Ayrıca İzmir Tarım ve Orman İl ve İlçe Müdürlükleri'nde görevli personelin görüşlerine de başvurulmuştur. Her mahalleye düşen anket sayısının belirlenmesinde mahallelerin meyve/sebze üretim miktarının ilçe toplam üretim miktarına oransal katkısı dikkate alınmıştır. Anketler toplam 72 mahallede gerçekleştirilmiştir. Yapılan anketlerin ilçeleri temsil etmesi açısından seçilen her ilçede minimum beş anket yapılmasına azami özen gösterilmiştir. İlçelerde anket yapılan mahallelerin dağılımı Çizelge 2'de verilmiştir.

Üretim aşamasında meydana gelen kayıplar üzerinde etkili faktörler, Beşli Likert Ölçeği (Güriş ve Astar 2014) kullanılarak oluşturulan yargılar ile değerlendirilmiştir. Elde edilen verilerin yorumu için siklık, yüzde ve ortalama gibi temel istatistiki yöntemlerden yararlanılmış ve Khi-kare analizi (Güngör ve Bulut 2008) ile meyve ve sebze üretimindeki kayıplar ile kayıp düzeyleri arasında anlamlı bir fark olup olmadığı incelenmiştir.

\section{Bulgular}

\subsection{Meyve sebze üreticilerinin ve işletmelerin genel özellikleri}

Görüşülen işletmecilerin yaş ortalaması 52.29 yıl, tarımsal üretimdeki deneyim ortalamas1 28.66 y1l ve meyve-sebze üretimindeki deneyim ortalaması ise 26.18 yıldır.

Üreticilerin ağırlıklı olarak ilkokul mezunu oldukları (\%77.4), bunu sirasiyla ortaokul (\%8.9), lise (\%7.5) ve üniversite $(\% 5.5)$ mezunlarının izlediği belirlenmiştir. Sadece okuryazar olan üreticilerin oran 1 ise $\% 0.7$ 'dir.

Üreticilerin \%56.3'ü sadece tarımsal faaliyet ile geçinmekte iken, \%43.7'sinin tarım dışı gelir kaynakları bulunmaktadır.

Üreticilerin genel olarak mülk arazilerinde meyve ve sebze üretimi yaptıkları $(\% 64.5)$ bunu kira $(\% 25.7)$ ve ortakçılığın (\%5.5) izlediği belirlenmiştir. Ortalama arazi büyüklügü 33.94 da olan işletmeler arazi büyüklüklerine göre sınıflandırıldığında; $\% 31.5$ 'inin 10 dekarın altında ve \%54.9'unun ise 20 dekarın altında araziye sahip olduğu tespit edilmiştir.

Çizelge 1. Anketlerin ilçeler itibariyle dağılımı.

Table 1. Distribution of surveys by districts.

\begin{tabular}{|c|c|c|c|c|c|c|c|}
\hline \multirow{2}{*}{ İlçeler } & \multicolumn{6}{|c|}{ Meyve ve Sebzeler } & \multirow{2}{*}{ Toplam } \\
\hline & Üzüm & Kiraz & İncir & Domates & Hiyar & Biber & \\
\hline Bayındır & & 5 & & & 5 & & 10 \\
\hline Bergama & 5 & & & 6 & & 4 & 15 \\
\hline Beydağ & & & 5 & & & & 5 \\
\hline Bornova & & 5 & & & & & 5 \\
\hline Kemalpaşa & 5 & 10 & & & & & 15 \\
\hline Kınık & & & & 5 & & 5 & 10 \\
\hline Kiraz & & 5 & 5 & & 5 & & 15 \\
\hline Menderes & 5 & & & & & 5 & 10 \\
\hline Menemen & 5 & & & 5 & & & 10 \\
\hline Ödemiş & & & 5 & & 5 & & 10 \\
\hline Seferihisar & 5 & & & & & & 5 \\
\hline Selçuk & & & 5 & & & & 5 \\
\hline Tire & & & 6 & 5 & & 5 & 16 \\
\hline Torbalı & & & & 5 & 5 & 5 & 15 \\
\hline Toplam & 25 & 25 & 26 & 26 & 20 & 24 & 146 \\
\hline
\end{tabular}


Çizelge 2. Anketlerin mahallelere göre dağılımı.

Table 2. Distribution of surveys by villages.

\begin{tabular}{|c|c|c|c|c|c|c|c|c|}
\hline İlçe & Mahalle & Sayı & İlçe & Mahalle & Sayı & İlçe & Mahalle & Say1 \\
\hline \multirow[t]{5}{*}{ Bayındır } & Balcilar & 2 & Kınık & Değirmencieli & 3 & Ödemiş & Birgi & 5 \\
\hline & Buruncuk & 1 & & Fatih & 2 & & Kaymakçı & 1 \\
\hline & Çınardibi & 2 & & Poyracık & 3 & & Kuvvetli & 1 \\
\hline & Osmanlar & 2 & & Yayakent & 2 & & Ocaklı & 1 \\
\hline & Pinarlı & 3 & Kiraz & Aydoğdu & 2 & & Üzümlü & 2 \\
\hline \multirow[t]{8}{*}{ Bergama } & Alibeyli & 2 & & Başaran & 2 & Seferihisar & Çamtepe & 2 \\
\hline & Aşağıbey & 5 & & Cevizli & 2 & & Gödence & 2 \\
\hline & Aziziye & 2 & & Haliller & 4 & & Orhanlı & 1 \\
\hline & Bölcek & 2 & & Sırımlı & 1 & Selçuk & Belevi & 2 \\
\hline & Dağıstan & 1 & & Solaklar & 2 & & Gökçealan & 2 \\
\hline & Göçbeyli & 1 & & Tumbullar & 1 & & Havutçulu & 1 \\
\hline & Kadıköy & 1 & & Umurlu & 1 & Tire & Akkoyunlu & 2 \\
\hline & Zağnos & 1 & Menderes & Ataköy & 2 & & Alacalı & 4 \\
\hline \multirow[t]{3}{*}{ Beydağ } & Aktepe & 1 & & Çatalca & 1 & & İhsaniye & 1 \\
\hline & Halıköy & 2 & & Develi & 2 & & Kurşak & 1 \\
\hline & Yeşiltepe & 2 & & Efemçukuru & 2 & & Musalar & 1 \\
\hline \multirow[t]{3}{*}{ Bornova } & Beşyol & 1 & & Gölcükler & 1 & & Somak & 3 \\
\hline & Karaçam & 2 & & Yeniköy & 2 & & Topalak & 2 \\
\hline & Yaka & 2 & Menemen & Buruncuk & 1 & & Yeniçiftlik & 2 \\
\hline \multirow[t]{7}{*}{ Kemalpaşa } & Aşağıkızılca & 2 & & Çavuş & 2 & Torbalı & Çaybaşı & 2 \\
\hline & Bağyurdu & 2 & & Doğa & 2 & & Ertuğrul & 3 \\
\hline & Dereköy & 3 & & Haykıran & 3 & & Özbey & 7 \\
\hline & Halilbeyli & 1 & & Musabey & 2 & & Şehitler & 3 \\
\hline & Ören & 3 & & & & & & \\
\hline & Sütçüler & 1 & & & & & & \\
\hline & Yiğitler & 3 & & & & & & \\
\hline
\end{tabular}

Meyve ve sebze işletmelerinde en fazla yevmiye usulü dışarıdan kadın işçilerin çalıştırıldığı, yetiştirme döneminde çocuklar da dahil tüm aile bireylerinin üretimde yer aldığı, aile üyelerinin çalışılan gün sayısının ortalama 120.55 gün/yıl olduğu, hasat döneminde ise dişarıdan ortalama 44.57 gün işçi çalıştırıldığı belirlenmiştir.

İşgücü niteliğinin hasat öncesi, hasat aşaması ve hasat sonrası ortaya çıkan kayıplar üzerinde etkisi nedeniyle, üreticilerin işçi seçiminde dikkat ettikleri hususlar; 5'li Likert Ölçeği ile değerlendirilmiştir. Buna göre, ortalama 4.77 ölçek ortalaması ile işçilerin meyve-sebze tarımı ve hasadı konusunda deneyimli olmasının işçi seçimini etkileyen en önemli faktör olduğu; bunu 4.31 ölçek ortalaması ile işçi ücret taleplerinin takip ettiği, çalışan personelin hijyen gerekliliklerine uyumunun ise 3.76 ölçek ortalaması ile en az etkili faktör olduğu belirlenmiştir.

Kayıplar ile ilgisi nedeniyle, üreticilerin Bitki Koruma Ürünü tavsiyelerini aldıkları kaynaklar belirlenmiş ve buna göre, \%43.5 ile ilaç bayilerinin ilk sırada yer aldığı, bunu \%25 ile İlçe Tarım ve Orman Müdürlüğü'nde görevli personelin takip ettiği, toplamda \%19.2'lik k1smın ise diğer çiftçilerden tavsiye aldığı tespit edilmiştir.

\subsection{Meyve ve sebzelerde kayıp düzeyi}

Meyve ve sebze üreticileri ile yapılan anketlerde 2015/2017 yıllarına ait üretim verileri ve aynı yıllara ait kayıp miktarları sorulmuştur. Üreticilerden alınan bilgilere göre üretim aşamasında meydana gelen kayıpların yüzde (\%) değerleri hesaplanmıştır (Çizelge 3).

Buna göre üretim (hasat öncesi, hasat, hasat sonrası oluşan ve üreticiden satış aşamasına kadar bahçede/tarlada geçen süre) aşamasında; üzümde yaklaşık \%23.3; incirde yaklaşık \%18.3 ve kirazda \%17.54 oranında kayıp olduğu tespit edilmiştir. Sebzelerde ise hıyarda \%20.70, domateste yaklaşık \%9.7, biberde ise \%9.42'lik kayıp olduğu belirlenmiştir. Araştırma kapsamına alınan meyve ve sebzeler için tarımsal üretim aşamasında ortalama kayıp ise yaklaşık \%16.48 olarak belirlenmiştir.

Meyvelerde kayıpların (\%19.70) sebzelere oranla (\%13.27) daha fazla olduğu anlaşılmaktadır. Nitekim araştırmada seçilen meyveler ve sebzeler ile belirlenen kayıp oranları arasinda anlamlı bir ilişki olduğu da belirlenmiştir (Çizelge 4). Araştırma kapsamındaki ilçelerde özellikle kurutmalık ve salçalık olarak domates ve biber üretildiği, kurutmalık ürünler elle toplandıktan sonra kalan ürünlerin, salça sanayii için hammadde olarak toplandığı ancak bu toplamada kurutmalık ve sofralık kadar 
hassas işlemlerin yürütülmediği belirlenmiştir. Dolayısıyla ezilen, darbe alan ürünler ile renk, şekil, boyut özellikleri ile kalite kriterlerini karşılamayan ürünler, diğer ürünlere işlenerek bu ürünlerdeki kayıpların daha az olmasına katkı sağlamaktadır.

\section{3 Ürün kayıpları üzerinde etkili olan faktörler}

\subsubsection{Hasat öncesi kayıplar üzerinde etkili olan faktörler}

Hasat öncesi yoğun yağış gibi elverişsiz hava koşulları hastalıkların yanı sıra, kırılgan sebzelere, düşük kuru maddeli meyvelere neden olurken, yüksek sıcaklıklar güneş yanı̆̆ı gibi fizyolojik bozukluklara neden olabilmektedir. Hasat öncesi böcek istilası ise, meyvelerdeki hasat sonrası kayıpları önemli oranda artırmaktadır, çünkü bitki hastalıklarının bazıları sadece hasat sonrası kendilerini göstermektedir (HLPE 2014). Son yıllarda sözleşmeli üretimin yapıldığı büyük alanlarda, üretici dikim alanlarının bir kısmının üzerini kapatarak (sigorta alanı olarak) dolu, don, yağmur gibi hava koşullarından kaynaklanabilecek kayıplar azaltılmaya çalışılmaktadır.

Üreticilerin hasat öncesi ürün kayıpları üzerinde etkili olan faktörler konusundaki görüşleri 5'li Likert Ölçeği ile oluşturulan yargılarla değerlendirilmiştir. Buna göre; 4.66 ölçek ortalaması ile dolu, don, kar, yağmur, kuraklık gibi mevsimsel faktörlerin ilk sırada yer aldığı, bunu 4.41 ölçek ortalaması ile bitki hastalık ve zararlıları, 3.25 ölçek ortalaması ile yanlış kullanılan pestisit ve bitki gelişim düzenleyicilerinin izlediği belirlenmiştir (Çizelge 5). Bulgular mevcut literatürü destekler niteliktedir (Thompson 2007; IFPRI 2012; Meyer ve ark. 2017; Johnson ve ark. 2018a, 2018b; Oluk 2018; Salihoğlu ve ark. 2018; Demirbaş 2019; T.C. Dışişleri Bakanlığı 2019).

\subsubsection{Hasattaki kayıplar üzerinde etkili olan faktörler}

Üreticiler ürün kayıpları üzerinde, hasat esnasında etkili olan faktörlerden ilk üçünü; 5'li Likert Ölçek ortalamaları itibariyle, hasat zamanının doğru belirlenmemesi (gün olarak) (erken hasat/geç hasat) (3.59), üretimde bilgi ve tecrübe eksikliği (3.38), hasatta kullanılan alet, ekipman ve muhafaza kaplarının yetersizliği (3.04) olarak siralamaktadır Bunları sırasıyla uygun olmayan hasat yönetimi (3.02) ve hasat saatinin doğru belirlememesi (2.89) takip etmektedir (Çizelge 6).

Hasatta kayıplara etki eden üç ana faktör hasat olgunluğu, hasat zamanı ve hasat yöntemi olarak belirtilmektedir. Hasat olgunluğu, depolama ömrünün ve nihai üretim kalitesinin en önemli belirleyicisidir. Ürün kalitesini belirleyen boyut, şekil, lezzet, doku ve renk hasat zamanına bağlı olarak değişkenlik göstermektedir. Meyve ve sebzelerin büyük çoğunluğu elle hasat edilmektedir. Bununla birlikte, hasadın elle veya mekanik olarak gerçekleştirilmesi meyve ve sebzelerin bileşimi ve hasat sonrası kalitesi üzerinde önemli ölçüde etkili olduğu da belirtilmektedir (Ramjan ve Ansari 2018). Ancak her ürünün mekanik hasada elverişli olmadığı da bilinmektedir.

\subsubsection{Hasat sonrası kayıpları üzerinde etkili olan faktörler}

Hasattan sonra ortaya çıkan kayıpları etkileyen ilk üç faktör sırasıyla; 4.33 ölçek ortalaması ile aracı, tüccar ve şirketlerin fiyat politikası, 4.13 ölçek ortalaması ile hasat sonrası muhafaza koşulları ve 4.06 ölçek ortalaması ile arz/talep dengesizliğidir (ürünün tarlada kalması, satılamamas1). Bunları uygun olmayan istifleme şekli (3.42), uygun olmayan muhafaza kapları (3.35) ve bilgi, tecrübe eksikliği (3.20) takip etmektedir (Çizelge 7).

\subsection{Kayıpların azaltılmasinda etkili olabilecek faktörler hakkında üretici görüşleri}

Ürün kayıplarının azaltılmasında etkili olabilecek faktörlerden, üretici kooperatiflerinin kurulması 4.39 ölçek ortalama ile birinci sırayı, 4.19 ölçek ortalaması ile üreticilerin parsellerini birleştirmek suretiyle birlikte üretim gerçekleştirmesi ikinci sırayı, 4.17 ölçek ortalaması ile eğitim ve yayım faaliyetlerinin arttırılması ise üçüncü sırayı almıştır. Kırsal kalkınma desteklerinin arttırılması (4.15) ve tarımsal danışmanlık hizmetlerinin yaygınlaştırılması (4.07) ise sırasıyla diğer etkili faktörler olarak belirlenmiştir (Çizelge 8).

Çizelge 3. Üretim aşamasındaki meyve ve sebze kayıpları (\%).

Table 3. Fruit and vegetable losses in production (\%).

\begin{tabular}{|c|c|c|c|c|c|}
\hline Ürün & Sayı & Minimum & Maximum & Ortalama & Standart sapma \\
\hline Üzüm & 25 & 0.49 & 68.32 & 23.28 & 18.06 \\
\hline İncir & 25 & 0.00 & 58.33 & 18.28 & 15.19 \\
\hline Kiraz & 24 & 0.86 & 50.00 & 17.54 & 14.29 \\
\hline Hiyar & 15 & 2.54 & 46.67 & 20.70 & 14.31 \\
\hline Domates & 26 & 0.22 & 30.26 & 9.68 & 8.28 \\
\hline Biber & 22 & 0.20 & 29.76 & 9.42 & 9.90 \\
\hline Toplam & 146 & & & 16.48 & \\
\hline
\end{tabular}

Çizelge 4. Meyve ve sebze grupları ile kayıp oranları ilişkisi.

Table 4. The relationship between fruit and vegetable groups and loss rates.

\begin{tabular}{|c|c|c|c|c|c|}
\hline \multirow[b]{2}{*}{ Kayıp Oranları (\%) } & \multicolumn{2}{|c|}{ Üretilen ürün Grubu } & \multicolumn{3}{|c|}{ Ki-Kare } \\
\hline & Meyveler & Sebzeler & Değeri & sd & $\mathrm{P}^{*}$ \\
\hline $0-10$ aras1 & 24 & 34 & 11.274 & 4 & 0.024 \\
\hline $10-20$ aras 1 & 23 & 19 & & & \\
\hline $20-30$ aras1 & 9 & 4 & & & \\
\hline $30-40$ aras1 & 8 & 5 & & & \\
\hline 50 üzeri & 10 & 1 & & & \\
\hline
\end{tabular}


Çizelge 5. Hasat öncesi kayıplar üzerinde etkili olan faktörler.

Table 5. Factors affecting pre-harvest losses.

\begin{tabular}{|c|c|c|c|}
\hline Faktörler & Say1 & Ortalama* $^{*}$ & Standart Sapma \\
\hline Dolu, don, yağmur, kuraklık gibi mevsimsel faktörler & 142 & 4.66 & 0.557 \\
\hline Bitki hastalık ve zararlıları & 145 & 4.41 & 1.077 \\
\hline Yanlış kullanılan pestisit.(herbisit, fungusit vb.) ve bitki gelişim düzenleyicileri & 133 & 3.25 & 1.406 \\
\hline Bitki besleme uygulamalarındaki hatalar & 129 & 3.14 & 1.285 \\
\hline $\begin{array}{l}\text { Kültürel işlemlerin uygulanmaması (toprak işleme, yabancı ot temizliği, hastalıklı meyve } \\
\text { toplanmaması gibi) }\end{array}$ & 135 & 3.11 & 1.279 \\
\hline Toprak verimliliğini artırmak için aşırı gübreleme & 132 & 2.89 & 1.297 \\
\hline
\end{tabular}

* 1) Hiç katılmıyorum 2) Katılmıyorum 3) Kararsızım 4) Katılıyorum 5) Tamamen katılıyorum.

Çizelge 6. Hasat sırasında ortaya çıkan kayıplar üzerinde etkili olan faktörler.

Table 6. Factors affecting losses during harvest.

\begin{tabular}{|c|c|c|c|}
\hline Faktörler & Say1 & Ortalama $^{*}$ & Standart Sapma \\
\hline Hasat zamanının doğru belirlenmemesi) (erken hasat/geç hasat) & 145 & 3.59 & 1.484 \\
\hline Üretimde bilgi, tecrübe eksikliği & 125 & 3.38 & 1.480 \\
\hline Hasatta kullanılan alet, ekipman, muhafaza kaplarının yetersizliği & 135 & 3.04 & 1.395 \\
\hline Uygun olmayan hasat yöntemi & 133 & 3.02 & 1.368 \\
\hline Hasat saatinin doğru belirlenememesi & 133 & 2.89 & 1.383 \\
\hline
\end{tabular}

*1) Hiç katılmıyorum 2) Katılmıyorum 3) Kararsızım 4) Katılıyorum 5) Tamamen katılıyorum.

Çizelge 7. Hasattan sonra ortaya çıkan kayıpları etkileyen faktörler.

Table 7. Factors affecting post-harvest losses.

\begin{tabular}{|c|c|c|c|}
\hline Faktörler & Sayı & Ortalama $^{*}$ & Standart Sapma \\
\hline Arac1, tüccar ve şirketlerin fiyat politikası & 136 & 4.33 & 1.033 \\
\hline Hasat sonrası muhafaza şartları (sıcaklık) & 142 & 4.13 & 1.228 \\
\hline Arz/talep dengesizliği (ürünün tarlada kalması, satılamaması gibi ) & 137 & 4.06 & 1.229 \\
\hline Uygun olmayan istifleme şekli (yığın halinde, üst üste çuvalları atma vb.) & 130 & 3.42 & 1.408 \\
\hline Uygun olmayan muhafaza kapları & 129 & 3.35 & 1.423 \\
\hline Bilgi, tecrübe eksikliği & 123 & 3.20 & 1.465 \\
\hline
\end{tabular}

* 1) Hiç katılmıyorum 2) Katılmıyorum 3) Kararsızım 4) Katılıyorum 5) Tamamen katılıyorum.

Çizelge 8. Kayıpların azaltılmasında etkili olabilecek faktörler konusunda üretici görüşleri.

Table 8. Farmer views on factors that may be effective in reducing the losses.

\begin{tabular}{|c|c|c|c|}
\hline Faktörler & Say1 & Ortalama* $^{*}$ & Standart Sapma \\
\hline Üretici kooperatiflerinin kurulması & 141 & 4.39 & 0.876 \\
\hline Birlikte üretim projelerinin yaygınlaştırılmasının sağlanması & 138 & 4.19 & 1.036 \\
\hline Eğitim ve yayım faaliyetlerinin artırılması & 136 & 4.17 & 0.970 \\
\hline Tarımsal kırsal kalkınma desteklerinin artırılması & 142 & 4.15 & 1.100 \\
\hline Tarımsal danışmanlık hizmetlerinin yaygınlaştırılması & 137 & 4.07 & 1.072 \\
\hline
\end{tabular}

*1) Hiç katılmıyorum 2) Katılmıyorum 3) Kararsızım 4) Katılıyorum 5) Tamamen katılıyorum.

\section{Tartışma ve Sonuç}

Araştırmada meyve ve sebze üreten tarım işletmelerinde ortaya çıkan kayıplar ve bunların üzerinde etkili olan faktörler incelenmiştir. Elde edilen sonuçlar büyük ölçüde literatürle tutarlıdır ve üreticilerin alınabilecek önlemler konusundaki farkındalığı yüksek bulunmuştur. Kayıpların azaltılması için alınabilecek bazı teknik önlemler üründen ürüne değişmekle birlikte, çoğu önlem tüm meyve ve sebze grubu için geçerlidir. Nitekim, mevsimsel faktörler nedeniyle oluşan kayıplar tüm ürünleri etkilemekte ve son yıllarda ekonomik değeri yüksek olan bazı ürünlerin üretiminde farklı uygulamalara gidilmektedir. Örneğin, üzüm yetiştiriciliğinde bağların üzerinin polietilen örtülerle kapatılarak, yağmurun etkisi azaltılmakta ve bitki hastalıklarına karşı korunma sağlanabilmektedir (TOB 2019b). Yine kiraz çok yüksek ve çok düşük sıcaklıklara dayanıksız bir meyvedir. Çiçeklenmeye yakın dönemde olan yağışlar döllenmeye engel olurken, meyvenin olgunlaşma dönemine yakın olan yağışlar meyve çatlaması yaparak kayıplara neden olabilmektedir (TOB 2019c). Son yıllarda İyi Tarım Uygulamalarına (İTU) yer verilen büyük kiraz bahçelerinde uygulanan örtü sistemi, yağmur, dolu vb. etkilere karşı bahçeleri koruyarak kayıpları azaltmaktadır.

Tarımsal üretim aşamasında meydana gelen kayıpların bir diğer nedeni ise bitki hastalık ve zararlılarıdır. Araştırmada mevsimsel faktörlerden sonraki hasat öncesi kayıp nedeni, bitki hastalık ve zararlıları (4.41) olarak tespit edilmiştir. Hastalık ve zararlılara karşı öncelikle kültürel önlemler alınmalı (hastalıklı bitki artıkları ve meyvelerin bahçe/tarlalardan uzaklaştırılması gibi) sonrasında ise biyolojik ve son çare olarak gerekirse kimyasal mücadele yapılmalıdır. Araştırmada yanlış kullanılan pestisitler hasat öncesi kayıp nedenleri arasında üçüncü sırada bulunmuştur. Üreticilerin bitki hastalık ve zararlıları konusunda yeterli bilgi sahibi olması ve zamanında alacakları uygun tedbirler ile kayıpların önüne geçilmesi mümkündür. Özellikle 
kiraz, incir, üzüm gibi çok yıllık bitkilerde gerek hastalık gerekse diğer sebeplerle toplanmayan ve ağaçta kalan ürünler zamanla toprağa düşmektedir. Düşen meyvenin toprağa fungal, bakteriyel hastalıkları bulaştırması, böcekler için besin kaynağı olması, toprağın PH değerini bozması yanı sıra hastalıklar yayılmakta ve sonraki yıllarda da hastalığın görülmesine ve dolayısıyla ürün kayıplarının oluşmasına neden olmaktadır. Domates, salatalık, biber gibi tek yıllık bitkilerde ise ürünler hastalık ve diğer sebeplerle tarlada kalsa bile sürülerek uzaklaştırılması çok yıllık bitkilere nazaran daha kolaydır. İTU'nun yaygınlaştırılması, tarımsal üretimde yapılan işlemlerin kayıt altına alınmasını, toprak, su, yaprak analizlerinin düzenli yaptırılarak bitki besleme hatalarından kaynaklanan kayıpları azaltacağı, hatalı bitki koruma ürünü kullanımının önüne geçeceği, taşıma ve muhafazada uygun ekipman kullanımını sağlayacağı gibi olumlu etkiler nedeniyle önerilmektedir (Demirbaş 2019). İTU'nun yaygınlaştırılması için ise dekar başına verilen İTU destekleme ödemelerinin arttırılmasının teşvik edici olacağı değerlendirilmektedir.

Ayrıca, üreticilerin bu kayıplardan en az etkilenmesi için meteoroloji ile ilgili kritik uyarıları takip etmelerini sağlayacak uygulamaların (ak1llı telefon aplikasyonları gibi) yaygınlaştırılması, meteorolojik zararlara karşı bahçelerde yeni uygulamalara yatırım yapılması da kayıpların azaltılmasında etkili olabilecektir (Demirbaş 2018b).

Araştırmada hasatta meydana gelen kayıpların en önemli sebebinin hasat zamanının doğru belirlenememesi olduğu tespit edilmiştir. Örneğin, kirazda, çeşide özgü renk ve iriliğe ulaştıklarında, yeme olumu döneminde elle hasat edilmesi önerilmektedir (TOB 2016a). İncirde hasat zamanı meyvenin taze veya kurutmalık olarak değerlendirilmesine bağlı olarak değişmektedir. Kuru incir üretiminde, ağaç üzerinde kendi halinde buruklaşarak toprağa düşen kuru meyveler toplanarak kurutulmaya bırakılmaktadır (Şahin ve ark. 2012). Taze incirde ise neredeyse tamamen olgunlaşmış incirlerin hasat edilmesi gerekmektedir. Taze incirde kabuk rengi ve et sıkılığı olgunluk endeksleridir (Muhammed Asıf 2010). Domatesin hasat zaman1; pazara olan uzaklığa, yol durumuna ve tüketici istekleri ile işleneceği ürün gibi faktörlere bağlı olmakla birlikte yeşilden kırmızıya kadar oluşan renk değişimi dikkate alınarak hasat zamanı belirlenmektedir (TOB 2016b). Biber, uygun büyüklüğe geldiğinde hasat edilmelidir. Salçalık ve kırmızı toz biber üretiminde ise meyveler tamamen kızarıncaya kadar beklenmelidir. Hıyarda ise ilk hasat için en uygun zaman meyvelerin normal çeşit iriliğinin (sofralık, turşuluk) 1/3'ü veya en fazla $1 / 2$ 'sine ulaştı̆̆ı zamandır. Hasadın gecikmesiyle meyveler fazla irileşmekte, şekli bozulmakta ve pazar değerini yitirmektedir (Tarım Kütüphanesi 2019).

Görüldüğü gibi, kayıplar üzerinde etkili olan faktörlerin bir çoğu deneyim kadar teknik bilgi de gerektirmektedir. Nitekim, araştırmada da kayıplar üzerinde üreticilerin bilgi ve tecrübe eksikliği ikinci en önemli faktör olarak belirlenmiştir. Yine araştırmada üreticilerin \%50.7'si Bakanlığın veya diğer kamu kurum ve kuruluşlarının tarımsal faaliyetler ile ilgili eğitimlerine katılmadığını belirtmiştir. Üreticilere kayıpların azaltılması için önerileri sorulduğunda ise eğitim ve yayım faaliyetlerinin artırılması öne çıkarılmıştır. $\mathrm{Bu}$ nedenle üreticilere yönelik eğitimlerle, yetiştirme ve hasat teknikleri konusundaki bilgi eksikliği giderilerek ürünlerin doğru zamanda ve doğru şekilde hasat edilmesi sağlanabilir (GYKMAEM 2018).

Araştırmada hasat sonrası ürün kayıplarının en önemli nedeni fiyat belirsizlikleri olarak değerlendirilmiştir
(Adanacığlu 2016). Bu durumda genellikle üretici ürününü hasat etmekten veya hasada devam etmekten vazgeçmekte ve mahsul tarlada/bağ/bahçede kalmaktadır. Bu durum özellikle domates ve biber gibi pazar değeri düşük ancak işçilik ve toplama masrafları yüksek olan ürünlerde ortaya çıkmaktadır. Nitekim, araştırmada da arz talep dengesizliği sonucu veya ekonomik olmaması nedeniyle ürünün tarlada kalması hasat sonrası kayıplarda bir diğer önemli faktör olarak tespit edilmiştir.

Hasat sonrası kayıpların diğer önemli bir nedeni ise hasattan sonra ürüne özgü uygun hasat sonrası teknolojilerin kullanılmamasıdır. Hasat sonrası teknolojiler arasında en önemlisi ürünlerin soğukta, modifiye ve kontrollü atmosferde muhafazasıdır. Özellikle kiraz, üzüm, incir gibi bahçe ürünlerinin kalitelerinin korunması, raf ömrünün uzaması ve bozulmalarının önlenmesi için hasat sonrası soğukta muhafaza son derece önemlidir (Doğan ve Erkan 2014). Nitekim, araştırmada hasat sonrası muhafaza şartlarının sağlanamaması hasat sonrası kayıp nedenleri arasında ikinci en önemli faktör olarak belirlenmiştir. Üretici örgütlenmesinin etkin düzeyde sağlanması ile soğuk hava depo yatırımı gibi koşulların daha kolay sağlanabileceği düşünülmektedir. Nitekim üretici önerileri de bu doğrultudadır.

\section{Kaynaklar}

Adanacioğlu H (2016) Factors affecting farmers' decisions to participate in direct marketing: A case study of cherry growers in the Kemalpasa District of Izmir, Turkey. Renewable Agriculture and Food Systems 32(4): 291-305.

Berjan S, Capone R, Debs P, Bilali H (2018) Food losses and waste: A global overview with a focus on Near East and North Africa region. IJAMAD. http:// www.ijamad.iaurasht.ac.ir. Erişim 31 Ağustos 2019.

Bilali H (2018) Research on food losses and waste in North Africa. The North African Journal of Food and Nutrition Research 2(3): 51-57.

Buzby JC, Wells HF, Hyman J (2014) The estimated amount, value, and calories of postharvest food losses at the retail and consumer levels in the United States. USDA Economic Research Service: Washington, DC, USA, EIB-121.

Capone R, Bennett A, Deps P, Bucatariu CA, Bilali HE, Smolak J, Lee WTK, Bottalico F, Diei-Ouadi Y, Toppe J (2016) Zero waste in the Mediterranean Natural resources, food and knowledge. FAO and CIHEAM.

Demirbaş N (2018a) Dünyada ve Türkiye'de gıda israfinı önleme çalışmalarının değerlendirilmesi. VIII. IBANESS Congress Series, Plovdiv, Bulgaria, s. 521-526.

Demirbaş N (2018b) Precision agriculture in terms of food security: Needs for the future. X. IBANESS Congress Series, Ohrid, Macedonia, pp. 308-313.

Demirbaş N (2019) İyi tarım uygulamaları ile meyve bahçelerinde ortaya çıkan üretim, hasat ve hasat sonrası kayıpları azaltılabilir mi?. XII. IBANESS İktisat, İșletme ve Yönetim Bilimleri Kongreler Serisi, Plovdiv, Bulgaristan, s. 289-296.

Doğan A, Erkan M (2014) Bahçe ürünlerinin muhafazasında yeni bir teknoloji: Palistore (palliflex) ortamında depolama. Meyve Bilimi 1(2): 1-6.

Escaler M, Teng P (2011) Mind the gap: Reducing waste and losses in the food supply chain. Centre for Non Traditional Security Studies INSIGHT.

FAO (2014) Food losses and waste in Latin America and the Caribbean.

FAO (2017) Policy measures for managing quality and reducing postharvest losses in fresh produce supply chains in South Asian countries, Rome. 
FAO (2019) Key facts on food loss and waste you should know!. http://www.fao.org/save-food/resources/keyfindings/en/. Erişim 17 Temmuz 2019

Gustavsson J, Cederberg C, Sonesson U, Van Otterdijk R, Meybeck A (2011a) Global food losses and food waste: Extent, causes and prevention. FAO and SIC, Dusseldorf, Germany.

Gustavsson J, Cederberg C, Sonesson U (2011b) Global food losses and food waste, save food congress. FAO and SIC, Düsseldorf.

Güngör M, Bulut Y (2008) Khi-kare testi üzerine. Doğu Anadolu Bölgesi Araştırmaları Dergisi: 84-89.

Güriş S, Astar M (2014) Bilimsel araştırmalarda SPSS ile istatistik. Der Kitabevi, ISBN: 978-975-353-418-5, İstanbul.

GYKMAEM (Gıda ve Yem Kontrol Merkez Araştırma Enstitüsü Müdürlüğü) (2018) Gıda zincirindeki hasat sonrası kayıları azaltmak için yenilikçi yaklaşımlar.

HLPE (The High Level Panel of Experts) (2014) Food losses and waste in the context of sustainable food systems; A report by the high level panel of experts on food security and nutrition of the committee on world food security, Rome.

Johnson LK, Dunninga RD, Bloomb JD, Gunter CC, Boyettec MD, Creamera NG (2018a) Estimating on-farm food loss at the field level: A methodology and applied case study on a North Carolina farm. Resources, Conservation \& Recycling 137: 243-250.

Johnson LK, Dunninga RD, Gunter CC, Bloomb JD, Boyettec MD, Creamera NG (2018b) Field measurement in vegetable crops indicates need for reevaluation of on farm food loss estimates in North America. Agricultural Systems 167: 136-142.

IFPRI (International Food Policy Research Institue) (2012) A changing global harvest. Global Food Policy Report. http://www.ifpri.org/gfpr/2012/agricultural-productivity. Erişim 27 Aralık 2019.

İTOİM (2018) İstatistik veri tabanı. http://izmir.tarimorman.gov.tr. Erişim 12 Kasım 2018.

Meyer HC, Frieling D, Hamer M, Oertzen G (2017) Food losses in supply chains for fruits, vegetables and potatoes between field and retail shelf in North-Rhine Westphalia, Germany. International Journal on Food System Dynamics, p. 24-30. (available online at www.centmapress.org). Erişim 27 Aralık 2019.

Muhammed Asif CC (2010) Effect of fruit hardening treatments on postharvest quality maintenance and shelf life extension of fig (Ficus carica L.) fruits at low temperature storage condition. Central Food Technological Research Institute, Mysore, India.
Oluk CA (2018) Yarı işlenmiş meyve ve sebzelerin muhafaza yöntemleri. Uluslararası Doğu Akdeniz Tarımsal Araştırma Enstitüsü Dergisi 1(1): 96-130.

Ramjan MD, Ansari MH (2018) Factors affecting quality of fruits and vegetables. Journal of Medicinal Plants Studies 6(6): 16-18.

Salihoğlu G, Salihoğlu NK, Uçaroğlu S, Banar M (2018) Food loss and waste management in Turkey. Bioresource Technology 248: 88-99.

Şahin B, Özen M, Köseoğlu İ, Konak R, Doğan Ö, Tutmuş E (2012) Kuru incir yetiştiriciliği ve aflatoksin yönetimi el kitabı. Ege Üniversitesi Ziraat Fakültesi, Bahçe Bitkileri Bölümü, Erbeyli İncir Araştırma Enstitüsü Müdürlüğü, Ege Kuru Meyve ve Mamulleri İhracatçıları Birliği, İzmir, s. 70.

Tarım Kütüphanesi (2019) Hıyar yetiştiriciliği. http://www.tarimkutuphanesi.com/HIYAR_YETISTIRICILIGI_00 028.html. Erişim 31 Temmuz 2019.

T.C. Dışişleri Bakanlığı (2019) Bazı meyveler için hasat sonrası kayıpların ekonomik analiz raporu. http://www.postharvestproject.com/uploads/outputs/d3270dfd9d15-4b65-a2b9-9d13567be7e9.PDF. Erişim 12 Aralık 2019.

Thompson AK (2007) Preharvest factors on postharvest life. https://pub.epsilon.slu.se/9029/1/Ali_L_120906.pdf. Erişim 09 Şubat 2019.

TOB (2016a) Kiraz vişne hastalık ve zararlıları ile mücadele. https://www.tarimorman.gov.tr/GKGM/Belgeler/BitkiHizmetleri/ha stalik_zararlilari_ile_mucadele_dokumanlari/kiraz.pdf. Erişim 31 Temmuz 2019.

TOB (2016b) Domates hastalı ve zararlıları ile mücadele. https://www.tarimorman.gov.tr/GKGM/Belgeler/BitkiHizmetleri/ha stalik_zararlilari_ile_mucadele_dokumanlari/domates.pdf. Erişim 31 Temmuz $201 \overline{9}$.

TOB (2019a) Yıllara göre meyve ve sebze üretim miktarı. https://www.tarimorman.gov.tr/Konular/Bitkisel-Uretim/Tarla-VeBahce-bitkileri/ Urunler-Ve-Uretim. Erişim 21 Temmuz 2019.

TOB (2019b) Bağ hastalık ve zararlıları ile mücadele. https://www.tarimorman.gov.tr/GKGM/Belgeler/BitkiHizmetleri/ha stalik_zararlilari_ile_mucadele_dokumanlari/bag.pdf. Erişim 31 Temmuz 2019.

TOB (2019c) Kiraz yetiştiriciliği. https://ankara.tarimorman.gov.tr/Belgeler/liftet/kirazyetistiriciligi.p df. Erişim 29 Temmuz 2019. 